\title{
The Mediating Role of Absorptive Capacity in the Relationship between Research Community Participation and Open Innovation
}

\author{
Rabiah Eladwiah Abdul Rahim*, Nor'ashikin Ali, and Juraifa Jais \\ College of Graduate Studies, Universiti Tenaga Nasional, Kajang, Malaysia
}

\begin{abstract}
This study aims to investigate the factors influencing research community participation and open innovation through the mediating role of absorptive capacity from the lens of Resource Based View and Dynamic Capability perspectives. Based on a survey of 115 senior engineering faculties from three research universities in Malaysia, this study applies the Structural Equation Modelling (SEM) to investigate the research model. The findings demonstrate that top management support has a major impact on research community participation. The findings also suggest that absorptive capacity mediates the association between research community participation and open innovation capability. This study provides a theoretical basis on the resources and capability that are pertinent for open innovation. From a practical perspective, the relationships among research community participation, absorptive capacity, and open innovation suggest how universities can promote research community participation and assess their absorptive capacity to achieve open innovation.
\end{abstract}

\section{Introduction}

Due to the turbulence in the market and increased competition, the firm has moved its focus from internal R\&D to collaborative partnerships with external sources. The means of accessing and receiving knowledge from external sources and actors are termed as open innovation search (Parida, Westerberg, \& Frishammar, 2012). Open innovation (OI) is a method of gaining access to a wide range of external players and knowledge channels with the goal of accelerating innovation by leveraging information flows (Chesbrough, 2006). A number of factors, including the shortening of product life cycles, increased global competitiveness, and growing research and development expenditures.

Knowledge is formed in communities (Johnson, 2010; Kassicieh, 2010). Scientists in their communities are usually the ones who capture and produce tacit experiential knowledge (Giudice, Peruta, \& Maggioni, 2013). According to Gertler (2003), the absorptive ability must first be formed in order to absorb tacit and codified knowledge in the proper proportions. Absorptive capacity, defined as the ability to perceive new knowledge, assimilate it, and apply it to commercial purposes (Cohen \& Levinthal, 1990), should be used in knowledge

\footnotetext{
*rabiah@uniten.edu.my
} 
communities to improve tacit and explicit knowledge exchange, which is a critical component of innovation.

Several studies have examined open innovation in universities (Abdul Razak, Murray, \& Roberts, 2014; Draghicia, Babanb, Gogana, \& Ivascua, 2015; Villasalero, 2014). However, lack of research studies the impact of research communities towards open innovation. Also, while studies on absorptive capacity on open innovation have been addressed (Cheng \& Huizingh, 2014; Geum, Kim, Son, \& Park, 2013; Sáenz, Revilla, \& Knoppen, 2014), little studies found examining this concept in the context of communities in higher education institutions.

In this study, we address these gaps by focusing on the factors influencing research community participation and its effect on open innovation. Also, the mediating role of absorptive capacity is examined. This study focuses on internal knowledge exploitation i.e outbound OI to examine the exploitation of universities' knowledge towards external parties. The structure of this paper is as follows. First, we describe the underlying theories and hypotheses of this study. Then, in the methodology section, we explain the methods of data collection and instruments. Next, we present findings and discussions. Finally, we address the significance of the results from theoretical and practical perspectives.

\section{Theoretical foundation}

\subsection{Resource Based View}

Using Resource Based View (RBV), this study develops the research framework, linking the relations between research community participation and open innovation through absorptive capacity. RBV of an organization is referred as an economic instrument to gauge the firm resources. Barney (1991) added sustained competitive advantage can be attained if the resources are valued, rare, unique and irreplicable resources, which further lead to greater performance. In relation to $\mathrm{RBV}$, research community participation is an inimitable resources and competences that could increase value to the organization. Research community provides a platform to an effective dissemination of tacit knowledge through social relations and collaboration.

\subsection{Dynamic Capabilities}

The Dynamic Capabilities approach later emerged in the 1990s as an extension of RBV to overcome limitations of RBV. Helfat et al. (2007) explained that a dynamic capability as the capacity of an organization to purposefully create, extend or modify its resource base. Thus, organisation's survival is determined by ability to renew and reconfigure. In a changing business environment, knowledge is important to create value, improve and maintain competitive advantage (Teece, Pisano, \& Shuen, 1997). Absorptive capacity is the ability to recognize, integrate, modify, and apply outward knowledge (Cohen \& Levinthal, 1990). Absorptive capacity are frequently measured quantitatively (Lichtenthaler, 2009).Therefore, absorptive capacity is integrated in the theoretical framework to examine innovation at the team level. Based on RBV and Dynamic Capabilities theories, this study describes a framework to investigate how universities can optimize their research communities towards open innovation through absorptive capacity.

\subsection{Hypotheses}


Top management is one of the most significant possible influencers on organisational knowledge (Connelly \& Kelloway, 2003). The success or failure of a community's activities is largely determined by management (Aljuwaiber, 2016). As a result, more research into top management and employee perceptions of the role of communities and their relevance to the organisation is required (Annabi, McGann, Pels, Arnold, \& Rivinus, 2012).

New ideas and their accompanying change will not disrupt the culture of a firm that values openness (Mueller, 2014). New ideas and trends are seen as opportunities to grow and demonstrate how adaptable its members are to change (Day, 199).

The structure of an organisation offers a framework for actions and interactions, and it has the capacity to either facilitate or obstruct productive operations. Hierarchical or bureaucratic systems take time and slow down knowledge flow (Perkmann and Walsh, 2007), but a flexible structure with easy access to people allows for smoother and faster knowledge flow (Mueller, 2014).

Knowledge externalization and socialization are important in developing human resource across the departments particularly in specialists group (Draghicia et al., 2015). Absorptive capacity can increase open innovation through improved capability to absorb external knowledge by members which further lead to innovative solutions. The employee involvement in sharing tacit knowledge may improve the ability to attain, adapt, transform and apply knowledge from external sources such as industry. Based on this literature, following hypotheses are proposed:

H1: Top management support for knowledge sharing will positively affect research community participation

H2: Openness will positively affect research community participation

H3: Organizational structure will positively affect research community participation

H4: Research community participation will positively affect absorptive capacity

H5: Absorptive capacity will positively affect open innovation

H6: Absorptive capacity mediates the relationship between research community participation and open innovation.

The proposed framework is shown is Figure 1.

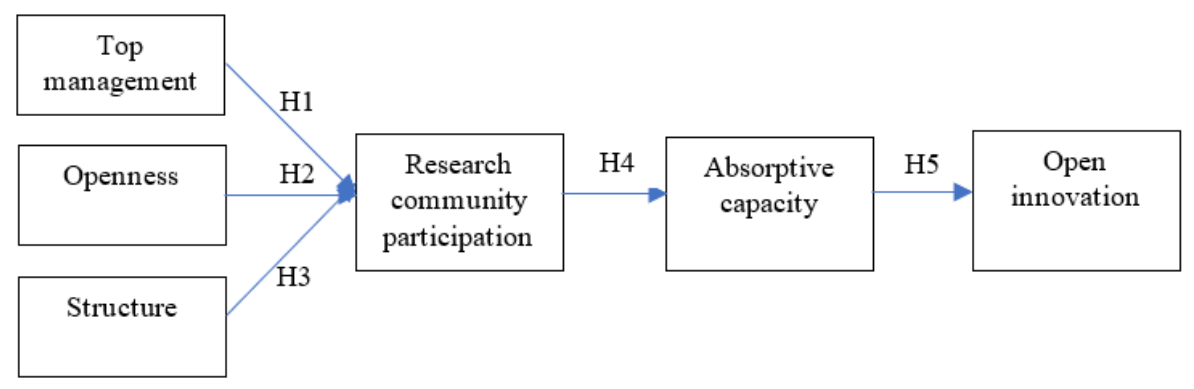

Figure 1. Conceptual framework

\section{Methodology}

\subsection{Measurement of variables}


We measured top management using a four-item reflective scale adapted from Tan and Zhao (2003). A three-item formative scale was used to measure structure which was adapted from Griffen and Moorhead (2001); Syed-Ikhsan and Rowland (2004); and Goh (2002). For openness, we measured this using a four-item reflective scale adapted from Baker and Sinkula (1999). For independent variable of research community participation, we adapted a four-item reflective scale from Koh and Kim (2004). Absorptive capacity was measured by adapting the 10 items developed by Pavlou and El Sawy (2006). Finally, the outbound open innovation is measured based on five-items reflective scale which was adopted from Ju, Chen, Yu, and Wei (2013).

The appropriate respondents were those who had experience in leading the team particularly for the past five years so that they might relate their experience with the current survey. The project leaders were regarded as the best candidates to answer the questions in this survey.

Given the fact that fields of technology received high attention with regards to open innovation, this study chooses engineering faculties of research universities in Malaysia as the respondents, of this study. The present study focuses on the project teams as the unit of analysis. In this study, a pre-test was conducted prior to the data collection. To do this, five engineering lecturers were asked to complete the survey. Overall, it appeared that these five lecturers had no difficulty in understanding the items or the instructions provided to complete the survey. Thus, this step resulted in no changes to the instruments. These responses were not used in the final study.

\subsection{Data collection}

The researcher selected the faculties from engineering departments ranging from senior lecturers' academic titles and above from research universities that the main campuses are located in the Klang Valley, Malaysia. From 531 distributed mail surveys, 120 responses were received which made a $22.5 \%$ response rate.

\section{Results and analysis}

\subsection{Data screening}

The data set was screened for issues such as the disqualified respondents, missing data, suspicious response patterns and outliers. This led to the removal of two cases which made 115 respondents remained.

\subsection{Demographic details}

The demographic profile shows that $62 \%$ of the respondents are working more than 8 years in the university, 11.3 have working experience between $6-8$ years, $14.8 \%$ have $3-5$ years working experience and $12.2 \%$ have less than 3 years working experience in their respective universities. In term of communities' participation, $21 \%$ of respondent participate in less than 2 communities, 54\% participate in 3-5 communities, $11.3 \%$ were involved in 6-9 communities and $14 \%$ were involved more than 10 communities.

\subsection{Model estimation and results evaluation}

Constructs should be modelled as formative if the following decision rules apply: causality flows from indicators to constructs, indicators do not have to be interchangeable, and 
covariation between indicators is not required; and the nomological net of indicators can differ, and they should be modelled as reflective if the opposite conditions apply (Jarvis, MacKenzie, and Podsakoff, 2003). The reflecting measurements were defined as top management (TM), openness (OP), research community participation (CP), and open innovation (OI), whereas the formatively assessed components were identified as structure and absorptive capability. The reflective and formative measurement models are presented in the following sub-sections.

\subsubsection{Reflective measurement model}

The composite reliability values of CP (0.935), OI (0.926), (0.945) and TM (0.956) demonstrated that these reflective constructs had high levels of internal consistency reliability. The analysis also shows that the loadings of CP, OI, OP and TM are well above the threshold value of 0.708 . The result also shows that the AVE values were well above the required minimum level of 0.5 . Thus, the measures of these reflective constructs had high levels of convergent validity and therefore all the items were remained.

For all the reflective constructs, it was found that each item loaded more highly on its own construct than on other constructs. For the discriminant validity at the construct level, Table 1 shows the results of the Fornell-Larcker criterion assessment. Overall, the square root of the AVE for the reflective constructs shows higher values than the correlations of these constructs with other latent variables in the path model. The model evaluation criteria for reflective measurement were met, providing support for the measures' reliability and validity.

Table 1. Results of Fornell-Larcker criterion

\begin{tabular}{|c|c|c|c|c|c|c|}
\hline Variables & AC & CP & OI & OP & ST & TM \\
\hline AC & 1 & 0 & 0 & 0 & 0 & 0 \\
\hline CP & 0.813 & $\mathbf{0 . 8 8 5}$ & 0 & 0 & 0 & 0 \\
\hline OI & 0.695 & 0.532 & $\mathbf{0 . 8 7 0}$ & 0 & 0 & 0 \\
\hline OP & 0.563 & 0.429 & 0.666 & $\mathbf{0 . 8 6 1}$ & 0 & 0 \\
\hline ST & 0.611 & 0.506 & 0.639 & 0.774 & 1 & 0 \\
\hline TM & 0.566 & 0.527 & 0.618 & 0.661 & 0.749 & $\mathbf{0 . 9 1 9}$ \\
\hline
\end{tabular}

\subsubsection{Formative measurement model}

The results of collinearity statistics shows that AC6 (tolerance of 0.154 and VIF of 6.478), exceeded the threshold value. Therefore, this indicator was removed which resulted in the collinearity statistics of the indicators being uniformly below the threshold values. In the context of PLS-SEM, tolerance values of 0.2 or lower and VIF values of 5 and higher indicate a potential collinearity problem (Hair et al., 2011). Based on the significance testing, there were 7 formative indicators have OLs lower than 0.5 which show non-significant weights (AC1, AC2, AC3, AC4, AC5, AC7, AC8). In respect to the bivariate correlations of the indicator to its latent construct, the loadings of all these indicators were above 0.5 . Thus, none of items was removed. 


\subsection{Structural model}

The structural model's analysis is depicted in Figure 3. H1 was supported since the link between top management and research community participation is significant $(\beta=0.334$, $t$ $2.640, p<0.01)$. The association between openness and research community involvement, as well as the relationship between structure and community participant, were not significant, hence $\mathrm{H} 2$ and $\mathrm{H} 3$ were rejected. Furthermore, these findings support $\mathrm{H} 4$ and $\mathrm{H} 5$, indicating that community participation has a direct impact on absorptive capacity $(\beta=0.811, \mathrm{t}=15.165$, $\mathrm{p}<0.01)$ and that absorptive capacity has a considerable impact on open innovation $(\beta=0.693$, $\mathrm{t}=10.027, \mathrm{p}<0.01$ ). The $\mathrm{R}$-square values ranged from 0.306 to 0.480 , indicating that the independent constructs explained a sufficient amount of the variance in the dependent constructs.

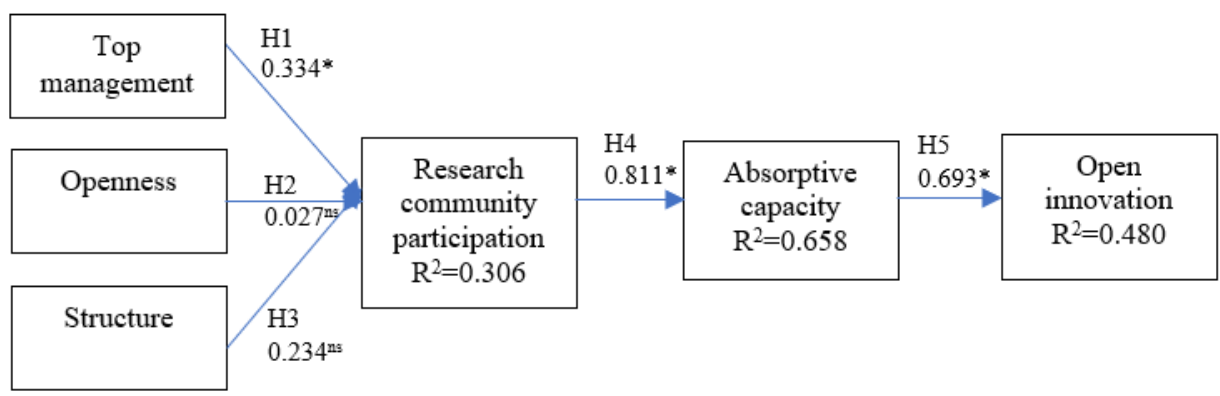

Figure 2. Structural model analysis ns: not significant, ${ }^{*} \mathrm{p}<0.01$ based on $\mathrm{t}_{(5000)}$, one-tailed test

\subsubsection{Mediator}

Based on Table 2, it is concluded that the relationship via AC mediator is significant $(\mathrm{t}=7.621, \mathrm{p}<0.01)$. To determine the strength of mediation, the assessment can be done by using VAF. The VAF equals the indirect effect (0.562) divided by the total effect (1.093) and has a value of 0.514 . Consequently, $51 \%$ of CP effect on $\mathrm{OI}$ is explained via the AC mediator. Since the VAF is larger than $20 \%$ but smaller than $80 \%$, this situation can be characterised as partial mediation.

Table 2. Mediation assessment

\begin{tabular}{|c|c|c|c|c|c|}
\hline Structural path & Coefficient & SD & t value & p value & Significant level \\
\hline CP->AC & 0.8114 & \multirow{2}{*}{0.074} & 7.621 & 0.000 & $* *$ \\
\hline AC->OI & 0.6928 & & & \\
\hline
\end{tabular}

\section{Discussion}

Using the Resource Based View and Dynamic Capabilities as the underlying theories, the objective of this study was to propose a conceptual model and then empirically test a model 
of linking $\mathrm{CP}$ and $\mathrm{AC}$ to open innovation capability. We examine the effect of research community participation on open innovation through the absorptive capacity as the mediating role in the relationship between research community participation and open innovation. We also explore the factors that influence the research community participation. Our empirical findings on the effects of research community participation, and absorptive capacity are not only consistent with prior studies (Kostopoulos, Papalexandris, Papachroni, \& Ioannou, 2011; Mueller, 2014) but also offer new findings on the association between research community participation, and absorptive capacity in enhancing open innovation in universities. The results of the structural equation modelling supported our main hypothesis that absorptive capacity mediates the relationship between research community participation and open innovation capability; hence supporting the previous studies that found the support of the mediating effect of AC related to innovation (Kostopoulos et al., 2011; Mueller, 2014). This means high absorptive capacity is potentially contributing to successful exploitation of new knowledge and skills toward producing more innovations. This can only be accomplished if there is the commitment of the research community in assimilating external knowledge resources into innovation. This indicates that absorptive capacity comes into play if there is a participation from research community. Building further on this insight, the moderating role played by absorptive capacity is a plausible means to expect more open innovation in environments characterised by a high degree or research community participation.

The results also show that in order for the research community to participate, the top management's involvement in research community promotes more abilities and opportunities to assimilate and exploit external knowledge. This is observed from the significant finding of the effect of top management on research community participation. This study provides additional empirical support to the studies on the role of top management in the success of failure of communities' activities (Aljuwaiber, 2016; Sun \& Anderson, 2012). Top management that shows high level of commitment will promote active participation of academicians in internal as well as external research communities.

While openness has been found to enhance research communities' participation in previous studies, this study found openness to be nonsignificant. In literature, openness is described as the culture that concerns on the new trends and ideas that bring improvements and change in the way community perform their work. In this study, openness may not affect the research community participation as the universities are already practising the culture of openness, where most researchers interact and collaborate with industries and other universities for knowledge transfer. Therefore, their participation in open innovation may not rely on the culture of openness. However, future research should look into more broadsense of openness degree.

Contrary to our expectations, this study did not find the structure to significantly affect the research community participation. Previous researches (Al-Alawi, Al-Marzooqi, \& Mohammed, 2007) argue that structure of organisation that includes participative decision making, easy information flow, committed teams and communities of practice is important for promoting the participation among the research community. However, since this study is in Malaysian context, this type of structure may not be significant due to our Asian culture that is less participative and open in interactions. The Asian culture is still practising bureaucracy level. Unless the top management initiates open communication, the research community may not be open in sharing their knowledge. That is also another reason top management is found to be significant while structure was found not significant. Furthermore, top management's commitment in enhancing participation of community for improving universities' absorptive capacity leads to increasing open innovation. 


\section{Conclusion}

The main focus of this article is to enhance understandings of how research community participation can be associated to open innovation through the mediating role of absorptive capacity. This study proposed a conceptual model representing the role of absorptive capacity as a mediator for research community participation to be involved in open innovation at higher learning institutions. This paper contributes to the management literature in two folds. First, this research provides an empirical evidence for the theoretical model. Our empirical study reaffirms the contribution of Cohen and Levinthal (1990) highlighting the fact that firms should be capable in recognising the value of new external knowledge, and assimilating and utilising that knowledge, which they refer to "absorptive capacity" in order to gain benefits from external knowledge flows. Second, this research, through empirical data, enhances understandings of researchers and practitioners on the link between research community participation, and absorptive capacity to promote open innovation. We conceptually identify and empirically examine how the role of absorptive capacity as mediator can be enhanced by the external drivers such as research community participation and top management commitment. Thus, it adds to the limited empirical evidence to support research in the innovation area that theoretically demonstrates the absorptive capacity as a catalyst for enhancement of organizational innovation (Murovec \& Prodan, 2009).

This study provides an important message for universities' stakeholders, who aim to develop sustainable competitive advantage. The greater commitment of leaders could suggest that research community participation is higher that leads to more effective absorptive capacity, which means that institutions need a true commitment from top management.

This study also offers some policy implications. First, by assessing how research community participation enhances absorptive capacity to affect open innovation, then a policy aimed at stimulating universities' absorptive capacity might be very effective in making the institutions more receptive to external knowledge flows, which in turn will stimulate local innovation. Secondly, the institutions set on formulating policies are advised to establish policies on the Intellectual Property Rights if they were to be effective in absorptive capacity.

This study is subject to a few limitations and some of them are avenues for future research. First, our data were self-reported assessments from universities' lecturers. It may suffer from common method bias. Second, our research is conducted in Malaysia, which may give the reason of nationality bias in our results. In future research, our model can be tested in different countries.

In conclusion, the work at hand demonstrates and recognises the value of absorptive capacity as a useful means for encouraging open innovation through the commitment and participation of community, which is influenced by top management. While it is suggested that further studies are required to strengthen the framework, the current study has responded to the calls of scholars who have stressed the need for empirical evidences that examines the relationship between absorptive capacity and open innovation from different perspective.

\section{REFERENCES}

Abdul Razak, A., Murray, P. A., \& Roberts, D. (2014). Open Innovation in Universities: The Relationship Between Innovation and Commercialisation. Knowledge and Process Management, 21(4), 260-269. 
Al-Alawi, A. I., Al-Marzooqi, Y. N., \& Mohammed, Y. F. (2007). Organizational culture and knowledge sharing: critical success factors. Journal of Knowledge Management, 11(2), $22-42$.

Aljuwaiber, A. (2016). Communities of practice as an initiative for knowledge sharing in business organisations: a literature review. Journal of Knowledge Management, 20, 731-748. Annabi, H., McGann, S. T., Pels, S., Arnold, P., \& Rivinus, C. (2012). Guidelines to align communities of practice with business objectives: An application of social media. Paper presented at the 2012 45th Hawaii International Conference on System Sciences.

Baker, W. E., \& Sinkula, J. M. (1999). The synergistic effect of market orientation and learning orientation on organizational performance. Journal of the Academy of Marketing Science, 27, 411-427.

Barney, J. B. (1991). Firm resources and Sustained competitive advantage. Journal of Management, 17(1), 99-120.

Cheng, C. C. J., \& Huizingh, E. K. R. E. J. (2014). When is open innovation beneficial? The role of strategic orientation. Prod. Innov. Manag., 31, 1235-1253.

Chesbrough, H. (2006). Open Innovation: The New Imperative for Creating and Profiting From Technology. Boston, MA.: Harvard Business Press.

Cohen, W. M., \& Levinthal, D. A. (1990). Absorptive Capacity: A New Perspective on Learning and Innovation. Special Issue: Technology, Organizations, and Innovation Administrative Science Quarterly, 35(1), 128-152.

Connelly, C. E., \& Kelloway, E. K. (2003). Predictors of employees' perceptions of knowledge sharing cultures. Leadership \& Organization Development Journal.

Day, G. S. (1994). Continuous learning about markets. California management review, 36(4), 9-31.

Draghicia, A., Babanb, C.-F., Gogana, M.-L., \& Ivascua, L.-V. (2015). A Knowledge Management Approach for The University-Industry Collaboration in Open Innovation. Procedia Economics and Finance, 23, 23 - 32.

Gertler, M. S. (2003). Tacit knowledge and the economic geography of context, or the undefinable tacitness of being (there). Journal of Economic Geography, 3(1), 75-99.

Geum, Y., Kim, J., Son, C., \& Park, Y. J. (2013). Development of dual technology roadmap (TRM) for open innovation: structure and typology. Eng. Technol. Manag., 30, 309-325.

Giudice, M. D., Peruta, M. R. D., \& Maggioni, V. (2013). Collective Knowledge and Organizational Routines within Academic Communities of Practice: an Empirical Research on Science- Entrepreneurs. J Knowl Econ, 4, 260-278.

Goh, S. (2002). Managing effective knowledge transfer: an integrative framework and some practice implications. Journal of Knowledge Management, 6(1), 23-30.

Greco, M., Grimaldi, M., \& Cricelli, L. (2016). An analysis of the open innovation effect on firm performance. European Management Journal, 34(5), 501-516.

Griffen, R., \& Moorhead, G. (2001). Organizational Behavior. New York, NY.: Houghton Middlin Company.

Hair Jr, J. F., Hult, G. T. M., Ringle, C. M., \& Sarstedt, M. (2013). A Primer on Partial Least Squares Structural Equation Modeling. Thousand Oaks: Sage.

Helfat, C. E., Finkelstein, S., Mitchell, W., Peteraf, M. A., Singh, H., Teece, D. J., \& Winter, S. G. (2007). Dynamic Capabilities: Understanding Strategic Change in Organizations. Malden, MA: Blackwell Publishing.

Huber, G. R., \& Power, D. J. (1985). Retrospective reports of strategic-level managers: Guidelines for increasing their accuracy. Strategic management journal, 6(2), 171-180.

Jarvis, C. B., MacKenzie, S. B., \& Podsakoff, P. M. (2003). A Critical review of construct indicators and measurement model misspecification in marketing and consumer research. Journal of Consumer Research, 30, 199-218. 
Johnson, S. (2010). Where good ideas come from: The natural history of innovation. New York, NY: Riverhead Books.

Ju, P.-H., Chen, D.-N., Yu, Y.-C., \& Wei, H.-L. (2013). Relationships among Open Innovation Processes, Entrepreneurial Orientation, and Organizational Performance of SMEs: The Moderating Role of Technological Turbulence.

Kassicieh, S. S. K. (2010). The knowledge economy and entrepreneurial activities in technology-based economic development. Journal of the Knowledge Economy, 1, 24-47.

Koh, J., \& Kim, Y. G. (2004). Knowledge sharing in virtual communities: an e-business perspective. Expert Systems with Applications, 26(2), 155-166.

Kostopoulos, K., Papalexandris, A., Papachroni, M., \& Ioannou, G. (2011). Absorptive capacity, innovation, and financial performance. Journal of Business Research, 64(12), 13351343.

Lichtenthaler, U. (2009). Absorptive Capacity, Environmental Turbulence, and the Complementarity of Organizational Learning Processes. Academy of Management Journal, 52(4), 822-846.

Lin, H. F., \& Lee, G. G. (2006). Effects of socio-technical factors on organizational intention to encourage knowledge sharing. Management decision.

Mueller, J. (2014). A specific knowledge culture: Cultural antecedents for knowledge sharing between project teams. European Management Journal, 32(2), 190-202.

Murovec, N., \& Prodan, I. (2009). Absorptive capacity, its determinants, and influence on innovation output: Cross-cultural validation of the structural model. Technovation, 29(12), 859-872.

Parida, V., Westerberg, M., \& Frishammar, J. (2012). Inbound open innovation activities in high-tech SMES: the impact on innovation performance. Journal of Small Business Management, 50(2), 283-309.

Pavlou, P. A., \& El Sawy, O. A. (2006). From IT leveraging competence to competitive advantage in turbulent environments: The case of new product development. Information Systems Research, 17(3), 198-227.

Perkmann, M., \& Walsh, K. (2007). University-industry relationships and open innovation: Towards a research agenda. International journal of management reviews, 9(4), 259-280.

Ringle, C. M., Wende, S., \& Will, A. (2005). SmartPLS 2.0 M3 Beta.

Sáenz, M. J., Revilla, E., \& Knoppen, D. (2014). Absorptive capacity in buyer-supplier relationships: empirical evidence of its mediating role. J. Supply Chain Manag., 50(18-40).

Sun, P. Y., \& Anderson, M. H. (2012). The combined influence of top and middle management leadership styles on absorptive capacity. Management learning, 43(1), 25-51.

Syed-Ikhsan, S., \& Rowland, F. (2004). Knowledge management in public organizations: a study on the relationship between organizational elements and the performance of knowledge transfer. Journal of Knowledge Management, 8(2), 95-111.

Tan, H. H., \& Zhao, B. (2003). Individual- and perceived contextual-level antecedents of individual technical information inquiry in organizations. The Journal of Psychology, 137(6), 597-621.

Teece, D. J., Pisano, G., \& Shuen, A. (1997). Dynamic capabilities and strategic management. Management Journal, 18(7), 509-533.

Urbach, N., \& Ahlemann, F. (2010). Structural Equation Modeling in Information Systems Research Using Partial Least Squares. Journal of Information Technology Theory and Application, 11(2).

Villasalero, M. (2014). University knowledge, open innovation and technological capital in Spanish science parks: Research revealing or technology selling. Journal of Intellectual Capital, 15(4), 479-496. 
Volberda, H. W., Foss, N. J., \& Lyles, M. A. (2010). Perspective-Absorbing the concept of absorptive capacity: How to realize its potential in the organization field. Organization science, 21(4), 931-951.

Yueqi, W., Bin, G., \& Yanjie, Y. (2017). Open innovation search in manufacturing firms: the role of organizational slack and absorptive capacity. Journal of Knowledge Management, 21(3), 656-674. 